\title{
Correspondence
}

\section{Postoperative malignant hyperthermia}

To the Editor:

The diagnosis of malignant hyperthermia $(\mathrm{MH})$ is sometimes quite straightforward, but can also be difficult.

Once a patient is labelled as "MH susceptible," however, implications for his medical care and that of his family are many and far-reaching. The diagnosis of MH should therefore be made with care.

Grinberg et al. recently reported on three patients who purportedly developed $\mathrm{MH}$ in the postoperative period despite the use of "safe" general anesthetics. 'We are unconvinced of the diagnosis in these cases.

The first patient was an "alcohol abuser" who developed a tachycardia and temperature elevation $4 \frac{1}{2}$ hours after a carpal tunnel release. Simultaneously a $\mathrm{pCO}_{2}$ of $7.45 \mathrm{kPa}$ (56 torr) was noted. Minute ventilation was not recorded. The CPK elevation was slight and not unusual for similar surgery. ${ }^{2}$ We believe that the narcotic administered might be responsible for the $\mathrm{CO}_{2}$ retention. Shivering, and possibly early DTs, might explain the temperature elevation.

In the second case MH was diagnosed on the basis of acidosis and hypercarbia in a peripheral venous blood gas (no minute ventilation noted), temperature of 38.3 four hours postoperatively, generalized muscle swelling, but a peak CPK of $1005 \mathrm{I} . \mathrm{U} . / \mathrm{L}$. There is no mention of whether dantrolene produced a prompt or delayed resolution of symptoms. It is unclear as to how generalized muscle swelling was diagnosed, although the CPK is higher than expected after such surgery. Bacteremia and sepsis or viremia might explain many of the symptoms.

The third patient developed hypertension, fever to 38.5 degrees associated with hypocarbia three hours after thyroid surgery. Peak CPK was 378.
Perhaps this patient has an underlying pheochromocytoma.

In the first two cases testing of biopsied muscle was reported consistent with $\mathrm{MH}$ on the basis of response to caffeine alone and to caffeine in the presence of halothane. The response to halothane only is not reported. Furthermore, the caffeine (and halothane-caffeine) specific concentration only are recorded.

Of the tests for $\mathrm{MH}$ using biopsied muscle the one that is agreed to be most specific by all centers for diagnosing $\mathrm{MH}$ is the response to halothane alone. ${ }^{3,4}$ Up to 15 per cent of the normal population will overlap the $\mathrm{MH}$ population in the caffeine-halothane contracture test. ${ }^{5.6}$ The response to caffeine alone can discriminate $\mathrm{MH}$ susceptibles from normals; however, the caffeine specific concentration (CSC) measurement has its problems. CSC is just one point in a dose response curve. Since not all muscle bundles respond in a similar manner because they vary in size, weight, and viability, there will be variations in the meaning of the generation of one gram of tension by a particular strip of muscle. However, the threshold for caffeine contracture, in particular the response to $2 \mathrm{~mm}$ caffeine appears to provide accurate discrimination of susceptibles from normals. . $^{3,4}, 7$

In summary, in order to make the clinical and laboratory diagnosis of MH convincing, far more information needs to be presented than appears in Grinberg's report. Tachycardia, fever, and even mild acidosis and $\mathrm{CO}_{2}$ retention are not sufficient by themselves to make the diagnosis of of $\mathrm{MH}$.

In reporting the results of muscle biopsy testing the response to halothane only, the threshold to caffeine and the amount of tension generated at threshold should be stipulated.

Henry Rosenberg MD

Department of Anesthesiology

Hahnemann University

Philadelphia, Pennsylvania

Gerald A. Gronert MD

Department of Anesthesiology

Mayo Clinic

Rochester, Minnesota 


\section{REFERENCES}

1 Grinberg G, Edelist G, Gordon A. Postoperative malignant hyperthermia episodes in patients who received "safe" anaesthetics. Can Anaesth Soc J 1983: 30: 273-6.

2 Roberts R, Gowda KS, Ludlerook PA, Sobel A Specificity of elevated serum MB creatine phosphokinase activity in the diagnosis of acute myocardial infarction. Am J Cardiol 1975; 36: 433-7.

3 Rosenberg $H$, Reed S. In vitro contracture tests for susceptibility to malignant hyperthermia. Anesth Analg 1983; 62: 415-20.

4 Okumura $F$, Cracker $B D$, Denborough $M A$. Identification of susceptibility to malignant hyperpyrexia in swine. Br J Anaesth 1979; 59: 171-6.

5 Rosenberg $H$. Report on the second international workshop on malignant hyperpyrexia. Ancsthesiology $1981 ; 54: 86-7$.

6 NeIson TE, Flewellen FH, Gloyna DF. Spectrum of susceptibility to malignant hyperthermia - diagnostic dilemma. Anesth. Analg 1983; 62: 545-52.

7 Gronert GA. Contracture responses and energy stones in quadriceps muscle from humans age 7-82 years. Hum Biol 1980; 52: 43-51.

\section{REPLY}

Thank you for the opportunity to respond to the letter of Drs. Rosenberg and Gronert.

We agree that the diagnosis of malignant hyperthermia may be difficult and must be made with care. Nor trearing an ongoing potential attack just because it is not classical may lead to serious consequences.

Our first patient surely had an $M H$ astack, possibly potentiated by the hypothermia and shivering. He had not been drinking for nine months. Besides he was quite lucid, alert and orientated and not tremulous in the recovery room just prior to the temperature elevation. making an alcohol withdrawal state quite unlikely. We agree that none of his laboratory values went severely awry. He was promptly treated with dantrolene, as well as supportive treatment. When we began treatment we already had the results of the muscle biopsy which was done at the same time as the carpal tunnel release. The caffeine contracture response, both in the presence and absence of halothane were well within the susceptible range as provided by Dr. Britt's laboratory. There was no coniracture in the presence of one per cent halathane, and, as the writers are aware, three per cent halothane is not used in Dr. Britt's laboratory, perhaps leading to some difference in results. There is not general agreement that the response to halothane is the most specific test for the diagnosis of $\mathrm{MH}^{1,2}$

Case two is even less in doubt. He had a biopsy because of family history of $\mathrm{MH}$ in the mother, and was associated with a more vigorous metabolic disturbance, as well as myoglobinuria.

Temperature and pulse rate fell to normai ranges within 20 minutes of the institution of dantrolene and supportive therapy, although through the next 24 hours further treatment was necessary to maintain him. The acidosis improved over the initial five hours of treatment, although again, over the initial course there was some fuctuation necessitating further treatment. Blood cultures done at the height of the fever were reported as showing no growth, so a bacteremia is quite unlikely, both on clinical grounds as well as on laboratory grounds. This man's biopsy showed spontaneous halothane contractures, as well as being sensitive to caffeine alone, and in the presence of halothane.

The third patient would not submit to muscle biopsy, so the diagnosis of $M H$ could not be confirmed. There was no previous or subsequent hypertension or any other metabolic disturbance to suggest pheochromocyloma, although catechoamine levels were not drawn to confrm that possibility. Again, we submit that to a clinician, a reaction of this sort, in the presence of this family history, is very suggestive of malignant hyperthermia.

The defense of the caffeine contracture test itself we leave to Dr. Brith. Ceriainly other laboratories use the test successfully to differentiate $\mathrm{MH}$ patients. ${ }^{2.3}$ We must be guided by the wisdom of our colleagues in the laboratory to test and diagnose the muscle and tell us that that patien does have malignant hyperthermia. It seems to us that no harm was done to any of the patients, as the first wo already had been labeled as $M H$ by their attending physician and the laboratory, and patient three was advised to have a muscle biopsy.

We suggest the occasional failure to diagnose $M H$ in a patient is a more grievous error that occasionally labelling a patient without $M H$ as having the disease.

R. Grinberg MD, G. Edelist MD FRCP(C),

A.S. Gordon MD FRCP(C)

Departments of Anaesthesia

and Medicine

University of Toronto

and Mount Sinai Hospital

Toronto, Ontario

\section{REFERENCES}

1 Kalow $W$, Britt BA, Richter $A$. The caffeine test of isolated human muscle in relation to malignant hyperthermia. Can Anaesth Soc J 1977; 24: 678-94.

2 Brownell AKW. Ed. Transcription of the proceedings of the third international workshop on malignant hyperthermia. Banff. Sept 30-Oct 2 , 1983.

3 Nelson TE, Flewellen PH, Gloyna DF. Spectrum of susceptibility to malignant hyperthermua: diagnostic dilemma. Anesth Analg 1983; 62: 545-52. 